\title{
Suppression of T-cell activation by pulmonary alveolar macrophages: dissociation of effects on TCR, IL-2R expression, and proliferation
}

\author{
D.H. Strickland, U.R. Kees, P.G. Holt
}

Suppression of T-cell activation by pulmonary alveolar macrophages: dissociation of effects on TCR, IL-2R expression, and proliferation. D.H. Strickland, U.R. Kees, P.G. Holt. CERS Journals Ltd 1994.

ABSTRACT: Suppression of local T-cell activation in the lower respiratory tract by resident pulmonary alveolar macrophages (PAMs) is believed to play an important role in the maintenance of local immunological homeostasis. However, the mechanism(s) by which pulmonary alveolar macrophages regulate $\mathbf{T}$-cell responses are poorly characterized.

The present study examines early events during the activation process in mitogenstimulated $T$-cell cultures, in which proliferation was completely blocked by the presence of pulmonary alveolar macrophages.

Despite inhibition of proliferation, the T-cells demonstrated normal $\mathrm{Ca}^{++}$flux, normal modulation of surface expression of CD3 and T-cell receptor $\alpha / \beta(\mathrm{TCR} \alpha / \beta)$, upregulation of interleukin-2 receptors $\alpha$ and $\beta$ (IL-2R $\alpha$ and IL-2R $\beta$ ), and secretion of high levels of interleukin-2 (IL-2).

Thus, pulmonary alveolar macrophage regulation of $\mathrm{T}$-cell activation appears to permit initial expression of effector function, but selectively inhibits further amplification of the overall $\mathrm{T}$-cell response by limiting clonal expansion of the activated effector T-cell.

Eur Respir J., 1994, 7, 2124-2130.
Institute for Child Health Research, Subiaco, Western Australia.

Correspondence: P.G. Holt Institute for Child Health Research PO Box 855

West Perth

Western Australia 6872

Keywords: Interleukin-2 interleukin-2 receptor

pulmonary alveolar macrophages suppression T-cell activation

T-cell receptor

Received: October 131993

Accepted after revision August 81994

This work was supported by the Asthma Foundation of Western Australia. P.G.H. is supported by the National Health and Medical Research Council of Australia.
Mature "resting" pulmonary alveolar macrophages (PAMs) from all species except the guinea-pig, have been demonstrated in many laboratories to suppress in vitro activation of homologous T-cells, and these findings have prompted suggestions that PAMs play an important censorial role in limiting the overall level of steady-state $\mathrm{T}$-cell responses at the sensitive blood-air interface in the peripheral lung (reviewed in [1, 2]).

A variety of secreted mediators have been demonstrated to contribute to PAM-mediated inhibition of T-cell proliferation in different in vitro models, and these include leukotrienes [3], prostaglandins [4, 5], transforming growth factor- $\beta$ (TGF- $\beta$ ) [6], interleukin-1 receptor antagonist (IL-1-Ra) [7], and nitric oxide [8]. Immunosuppressive steroid metabolites released via the activity of the enzyme dihydroepiandrosterone sulphatase in PAMs [9] may also play a role in this process. As well as direct effects upon T-cell proliferative capacity, PAMs have also been demonstrated to inhibit T-cell stimulation in vitro, via downmodulation of the major antigen presenting cell (APC) population present in lung tissue, the pulmonary dendritic cells (DCs) [10-12].

Recent experiments on drug modulation of PAM function(s) in experimental animals have provided more direct evidence for the operation of such a regulatory circuit in vivo. Thus, selective in situ depletion of resident PAMs in experimental animals via intratracheal administration of liposome-encapsulated dichloromethylene diphosphonate markedly increases the in vitro proliferative activity of lung-derived T-cells [13], and concomitantly increases local and systemic T-cell-dependent immune responses in vivo to inhaled antigens, in particular secondary response against antigens to which the animals were presensitized $[14,15]$. A notable feature of these findings was the differential stimulation of the immunoglobulin $\mathrm{E}(\mathrm{IgE})$ component of the immune response in the lung parenchyma and respiratory tract lymph nodes of PAM depleted animals [16], suggesting that this regulatory pathway may be of particular importance in control of local CD4+ T-helper-2 (TH-2) cell activation.

The molecular mechanism(s) underlying this potentially important regulatory process remain to be defined. The present study seeks to elucidate aspects of the in vitro immunosuppressive activity of PAMs in relation to early events in proliferating T-cell cultures, focusing particularly on modulation of the two principal classes of surface molecules which control the overall activation process, the T-cell receptor and interleukin-2 (IL-2) receptors. 


\section{Material and methods}

\section{Animals}

Inbred, specified pathogen free WAG rats, maintained under barrier conditions, were employed in the majority of these experiments. The overall findings from the study were subsequently validated in animals from the $\mathrm{BN}$ and Wistar Furth strains.

\section{Cell preparation and culture}

Methods for preparation of PAMs by bronchoalveolar lavage (BAL) and preparation of mononuclear cell suspensions from lymph nodes (LNs) and spleens, are as described in [11].

In experiments involving in vitro $\mathrm{T}$-cell activation, splenic or LN T-cells were cultured at $4 \times 10^{5}$ per $200 \mu \mathrm{l}$ in microplates in RPMI 1640 medium containing 5\% foetal calf serum (FCS) supplemented with $5.0 \mu \mathrm{g} \cdot \mathrm{ml}^{-1}$ concanavalin A (conA), in the presence or absence of PAMs, as detailed in [11]. Deoxyribonucleic acid (DNA) synthesis was measured at $48 \mathrm{~h}$, via incorporation of ${ }^{3} \mathrm{H}-$ thymidine (specific activity $5 \mathrm{Ci} \cdot \mathrm{mmol}^{-1}$ ) into DNA, and is shown below as mean disintegrations per minute (DPM) per culture [11]. IL-2 production in cultures was determined via the standard bioassay.

\section{Flow cytometry}

Flow cytometric analysis of surface marker expression employed an EPICS Elite cytometer, equipped with standard analytical software. Monoclonal antibodies (MoAbs) used were anti-rat CD5 (Ox19; pan T-cell) [17], anti-rat CD3 [18], anti-rat T-cell receptor $\alpha / \beta(\mathrm{TcR} \alpha / \beta)$ chain (R73) [19], anti-rat interleukin-2 receptor- $\alpha$ (IL-2R $\alpha$ ) (Ox39) [20], and anti-rat interleukin-2 receptor- $\beta$ (IL2R $\beta$ ) (NDS62) [21]. A mouse anti-human MoAb was employed as a background control.

T-cells were positively selected by gating on the panT-cell antibody Ox19, employing an Ox19-fluorescein isothiocyanate (FITC) conjugate prepared inhouse. The expression of surface CD3, TcR $\alpha / \beta$ or IL-2Rs was examined via staining with one of the MoAbs listed above, followed by biotinylated sheep-anti-mouse and streptavidin phycoerythrin (PE), and finally Ox19-FITC. Cell viability was determined by propidium iodide staining; analysis of DNA content of T-cells was performed using propidium iodide and ribonuclease (RNAse) as described previously [22].

\section{Calcium flux determination}

The determination of intracellular free calcium using the dye Indo-1 (Molecular Probes, Junction City, OR, USA) has been described previously [23, 24]. Briefly, T-cell populations were suspended in RPMI 1640 supplemented with $2 \%$ FCS and $10 \mathrm{mM}$ hydroxyethylpiperazine ethanesulphonic acid (HEPES), $\mathrm{pH}$ 7.4, at a concentration of $5 \times 10^{6} \cdot \mathrm{ml}^{-1}$. Cells were incubated with Indo-1, at a final concentration of $18 \mu \mathrm{M}$, at $37^{\circ} \mathrm{C}$ for $35 \mathrm{~min}$ in the dark. The loaded cells were subsequently maintained for at least $2 \mathrm{~h}$ prior to analysis at room temperature (RT), in the dark and in the presence or absence of PAMs, added at $10 \%$ of the T-cell concentration.

Immediately preceding flow cytometric analysis of calcium flux, the Indo-1 labelled cells were diluted to $1 \times 10^{6} \cdot \mathrm{ml}^{-1}$ in medium containing $1 \mathrm{mM} \mathrm{CaCl}_{2}$ and equilibrated at $37^{\circ} \mathrm{C}$.

For each experiment, measurement of unstimulated baseline levels of intracellular calcium bound Indo-1 was initially established. This was followed by the addition of the activating agent and measurement of the increase in the intracellular ionized calcium concentration, as determined by the increase in the ratio of blue/violet fluorescence of Indo-1. The results are expressed as calcium flux, being the ratio of Ca-bound (violet):unbound (blue) Indo-1, measured over a 5 min time-interval in response to the stimulant added after $1 \mathrm{~min}$.

\section{Data analysis}

Where applicable, comparisons between data groups were performed using the Student's paired t-test.

\section{Results}

\section{Suppression of in vitro $T$-cell proliferation by PAMs}

Figure 1 illustrates typical dose-response curves obtained via titration of increasing numbers of PAMs into cultures of splenic or LN lymphocytes, stimulated with

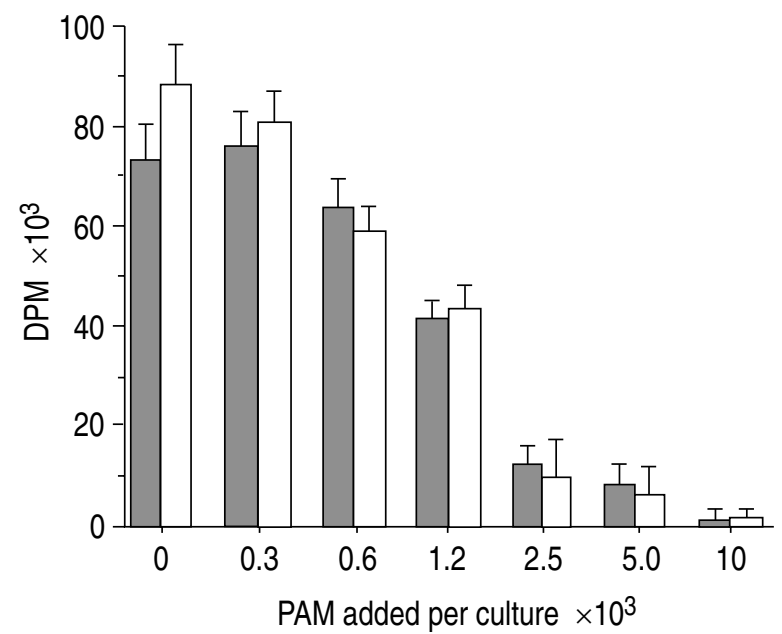

Fig. 1. - Effect of PAMs on splenic ( $\square$ ) and LN ( $\square$ ) Tcell responses to conA. PAMs were added in increasing numbers to $2 \times 10^{6} \cdot \mathrm{ml}^{-1} \mathrm{~T}$-cells and the cultures stimulated with conA $\left(5 \mu \mathrm{g} \cdot \mathrm{ml}^{-1}\right)$. Cells were cultured for 2 days and deoxyribonucleic acid (DNA) synthesis was measured via ${ }^{3} \mathrm{H}$-thymidine incorporation. Data are expressed as DPM (mean \pm SD) of triplicate cultures from a representative experiment $(\mathrm{n}>15)$. PAM: pulmonary alveolar macrophages; conA: concanavalin A; LN: lymph node; DPM: disintegrations per minute. 

sion of T-cell proliferation was achieved with the addiT-cell concentration. Viability of the T-cells at day 1 and day 2 was $>95 \%$ in the presence or absence of PAMs, suggesting that the mechanism of suppression involved inhibition of proliferation as opposed to cytotoxicity. In support of this conclusion, analysis of DNA content was determined on day 3 after initiation of the cultures, and the results indicated that whilst a significant proportion of the normal conA-stimulated T-cells progressed to the S/G2M phases of the cell cycle, T-cells stimulated with conA in the presence of PAMs did not. In a representative experiment, $67.4 \%$ of conA-activated cells were in $\mathrm{G} 0 / \mathrm{G} 1,14.6 \%$ had progressed to the $\mathrm{G} 2 \mathrm{M}$ phase, and $18 \%$ were in $\mathrm{S}$ phase. For T-cells stimulated with conA in the presence of PAMs, $92.2 \%$ of the T-cells remained in $\mathrm{G} 0 / \mathrm{G} 1$ phase.

\section{TcR downmodulation during in vitro activation}

Figure 2 shows surface expression of CD3 and TcR $\alpha / \beta$ at the $24 \mathrm{~h}$ time-point following initiation of T-cell cultures. The T-cells were gated on CD5, and the intensity of expression of TcR-associated surface molecules is shown as mean fluorescence intensity (MFI). CD5 expression decreased by variable amounts following activation. However, these small changes were restricted within the normal positive range.

In these experiments, parallel cultures were established containing $2 \times 10^{5}$ splenocytes $\cdot \mathrm{ml}^{-1}$ plus medium (Control), and the latter plus $5 \mu \mathrm{g}$ conA alone or with $10^{4}$ PAMs (equivalent to the top of the PAM dose curve in an optimal concentration of conA. Fifty percent supprestion of $10^{3}$ PAMs per culture, equating to $0.6 \%$ of the

figure 1). Cultures were analysed for TcR surface expression at the $24 \mathrm{~h}$ time-point, with parallel replicate cultures being subsequently assayed at $48 \mathrm{~h}$ to verify that lymphocyte proliferation was indeed completely inhibited.

In the cultures containing conA alone, vigorous T-cell proliferation occurred, and CD3 expression was downmodulated markedly compared to control cultures containing no mitogen (MFI 7.4 versus 0.5 in the representative experiment shown; over a series of 10 experiments the mean percentage reduction in MFI $( \pm \mathrm{SD})$ was $65 \pm 18$; $\mathrm{p}<0.001$ ). Downmodulation of $\mathrm{TcR} \alpha / \beta$ chain expression also occurred (MFI 7.6 to 2.4 in the example shown; mean percentage reduction over 10 experiments was $53 \pm 10 ; \mathrm{p}<0.001)$.

Consistent with the data of figure 1 , the cultures containing $10^{4}$ PAMs completely failed to proliferate, but, nevertheless, the T-cells exhibited CD3 and TcR $\alpha / \beta$ downmodulation, which was comparable to that occurring in nonsuppressed (PAM-free) cultures.

\section{$I L-2 R$ expression and $I L-2$ production in the presence of $P A M S$}

The experiments in figure 3 followed similar lines to those in figure 2, but additionally included control lymphocyte cultures containing PAMs without added mitogen. Expression of both the $\alpha$ and $\beta$ affinity receptors for IL-2 was clearly upregulated in proliferating (PAM-free) conA-stimulated cultures, and also in the cultures where proliferation was completely inhibited by the presence of PAMs. In addition, measurement of the concentration of bioactive IL-2 in the supernatant of

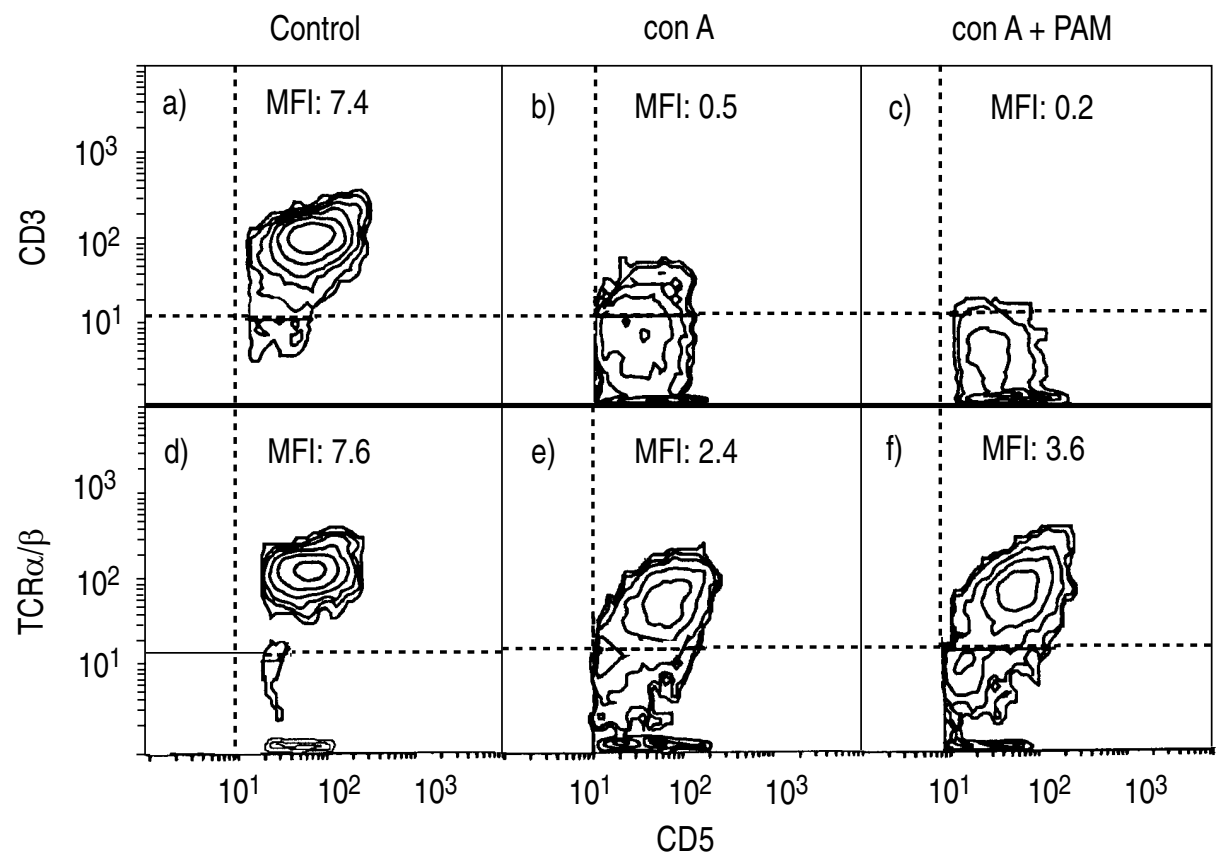

Fig. 2. - Flow cytometric analysis of the expression of CD3 and TcR $\alpha / \beta$ on splenic T-cells (gated for by double staining with CD5). T-cells were cultured at a concentration of $2 \times 10^{6} \cdot \mathrm{ml}^{-1}$ and stimulated with conA $\left(5 \mu \mathrm{g} \cdot \mathrm{ml}^{-1}\right)$ in the presence or absence of PAMs (added at $10 \%$ of the Tcell concentration). Control cultures had neither conA or PAMs added. Cultures were harvested at $24 \mathrm{~h}$ and stained for CD5 and CD3 or TcR $\alpha / \beta$, as described in Materials and methods; employing the control MoAbs to set the upper limit of background staining for PE (y axis) and FITC (x axis) indicated by the dotted lines. Values for MFI (arbitrary units) are shown for control cells and those exposed for 24 hr to con A, alone or in the presence of PAM, and are representative of a series of experiments $(n>15)$. TcR $\alpha / \beta$ : T-cell receptor $\alpha / \beta$; MoAb: monoclonal antibody; MFI: mean fluorescence intensity. For further abbreviations see legend to figure 1 . 

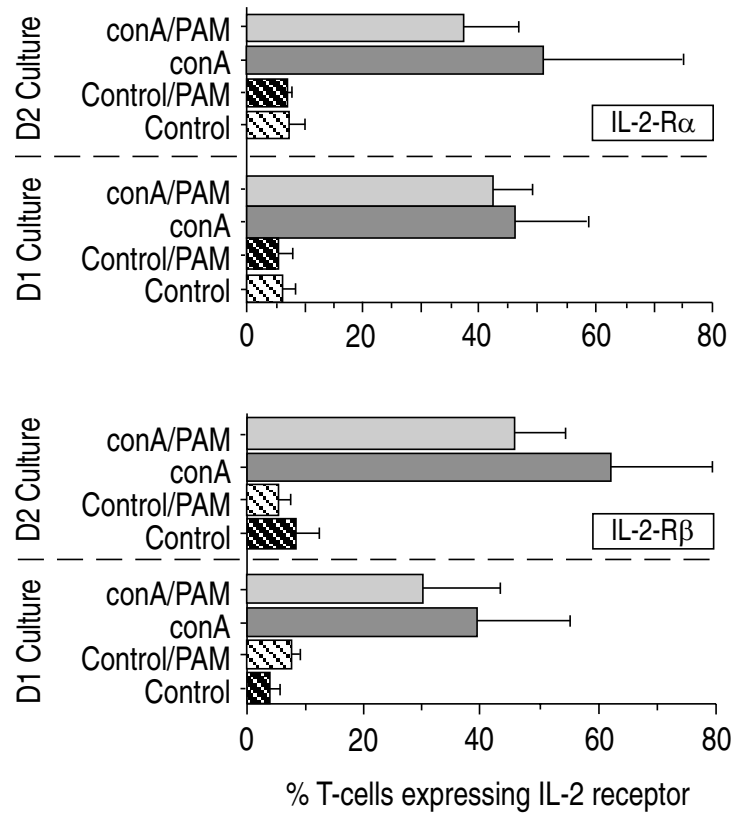

Fig. 3. - Effect of PAMs on the expression of IL-2 receptors on splenic T-cells following activation with conA. T-cells were cultured at a concentration of $2 \times 10^{6} \cdot \mathrm{ml}^{-1}$ and were either stimulated with conA $\left(5 \mu \mathrm{g} \cdot \mathrm{ml}^{-1}\right)$ or left unstimulated (Control). PAMs were added to parallel cultures at $10 \%$ of the T-cell concentration. Cultures were harvested at 24 and $48 \mathrm{~h}$ after initiation, stained for CD5 and IL-2R $\alpha$ or IL-2R $\beta$ and analysed by flow cytometry, as described in Materials and methods. Results are expressed as the mean \pm SD percentage of $\mathrm{T}$-cells that are expressing IL-2 receptors. IL- $2 \mathrm{R} \alpha$ and IL- $2 \mathrm{R} \beta$ expression was not significantly different $(0.1>\mathrm{p}<0.2)$ between cells stimulated in the presence versus absence of PAMs $(\mathrm{n}>10)$. IL-2: interleukin-2; IL-2R $\alpha$ and IL-2R $\beta$ : interleukin- 2 receptor $\alpha$ and $\beta$. For abbreviations see legend to figure 1 .

these cultures at the $24 \mathrm{~h}$ time-point (fig. 4) indicated the presence of high levels of IL-2 in the cultures containing PAMs, despite the failure of the lymphocytes to proliferate in the presence of PAMs. Although IL-2 secretion by T-cells was reduced in cultures containing PAMs in comparison to cultures free from PAMs, significant levels of IL-2 were still produced; and, furthermore, the addition of up to $1,000 \mathrm{U}$ recombinant IL-2 (rIL-2) to T-cell cultures containing PAMs failed to demonstrate any significant increase in the capacity of the lymphocytes to proliferate (table 1).

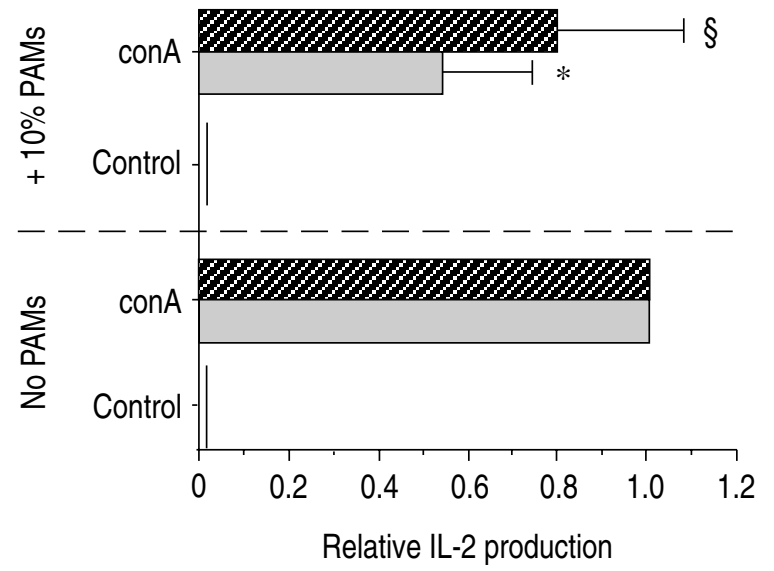

Fig. 4. - Production of bioactive IL-2 by splenic ( $\square$ ) and LN ( 2 ) T-cells in the presence and absence of PAMs. T-cells were cultured at $2 \times 10^{6} \cdot \mathrm{ml}^{-1}$ and either stimulated with conA $\left(5 \mu \mathrm{g} \cdot \mathrm{ml}^{-1}\right)$ or left unstimulated (Control). PAMs were added to parallel cultures at $10 \%$ final T-cell concentration. Culture supernatants were harvested after $24 \mathrm{~h}$ and assayed for the presence of bioactive IL-2 using the standard CTLL-2 bioassay. Results are expressed as the mean \pm SD $(n=6)$ amount of IL-2 produced and normalized to T-cells stimulated with conA alone (absolute levels of IL- 2 in the control cultures averaged $17.5 \mathrm{U} \cdot \mathrm{ml}^{-1}$. *: $\mathrm{p}<0.001$ versus conA without PAMs; $\S: \mathrm{p}<0.01$ versus conA without PAMs.

$\mathrm{Ca} a^{++}$flux

The calcium flux ratio was determined for splenic Tcells in the presence and absence of PAMs using conA as the mitogenic signal, acting via functional CD3/TcR complex [25]. Calcium ionophore A23187 (CaI), which provides maximal stimulus for $\mathrm{Ca}^{++}$mobilization, acting via TcR independent mechanisms, was used as a positive control. To determine the effect of PAMs on T-cell calcium flux potential, Indo-1 loaded cells were incubated with PAMs (at concentrations equivalent to the top of the dose curve in figure 1 ) for at least $2 \mathrm{~h}$ prior to addition of the activating agent, and were retained with the Tcells during analysis.

The response of a normal T-cell culture stimulated with $\mathrm{CaI}$ in the presence and absence of PAMs, is illustrated in figure 5. The results are representative of the profile defining the blue:violet fluoresence ratio for all the individual T-cells analysed over time. For determination of the $\mathrm{Ca}^{++}$flux ratio for the overall culture, the

Table 1. - The effect of recombinant IL-2 (rIL-2) on splenic T-cell responses to conA in the presence of PAMs

\begin{tabular}{llccccc}
\hline \multirow{2}{*}{$\mathrm{rLL}-2$} & \multicolumn{2}{c}{ Experiment 1 } & \multicolumn{2}{c}{ Experiment 2 } & \multicolumn{2}{c}{ Experiment 3 } \\
$\mathrm{U} \cdot \mathrm{ml}^{-1}$ & No PAMs & 5\% PAMs & No PAMs & 5\% PAMs & No PAMs & 5\% PAMs \\
\hline 0 & $45273 \pm 4879$ & $95 \pm 103$ & $23268 \pm 1008$ & $118 \pm 22$ & $50562 \pm 5782$ & $328 \pm 56$ \\
10 & $60487 \pm 8528$ & $127 \pm 481$ & $42754 \pm 6630$ & $76 \pm 20$ & $49152 \pm 6082$ & $356 \pm 308$ \\
100 & $78256 \pm 10213$ & $157 \pm 693$ & $42044 \pm 2270$ & $162 \pm 10$ & $53154 \pm 1098$ & $126 \pm 63$ \\
1000 & $80483 \pm 9154$ & $365 \pm 227$ & ND & $147 \pm 36$ & $56764 \pm 3236$ & $232 \pm 40$ \\
\hline
\end{tabular}

Data are shown for three separate representative experiments and are expressed as mean DPM \pm SD of triplicate cultures. Splenic T-cells were cultured at a density of $2 \times 10^{6} \cdot \mathrm{ml}^{-1}$ stimulated with conA $\left(5 \mu \mathrm{g} \cdot \mathrm{ml}^{-1}\right)$ in the absence or presence of PAMs added at 5\% final T-cell concentration. Recombinant IL-2 was added in increasing doses at the initiation of the culture. Cells were cultured for 2 days and deoxyribonucleic acid (DNA) synthesis was measured via ${ }^{3} \mathrm{H}$-thymidine incorporation. ND: not done; PAM: pulmonary alveolar macrophage; conA: concanavalin A; IL-2: interleukin-2; DPM: disintegrations per minute. 


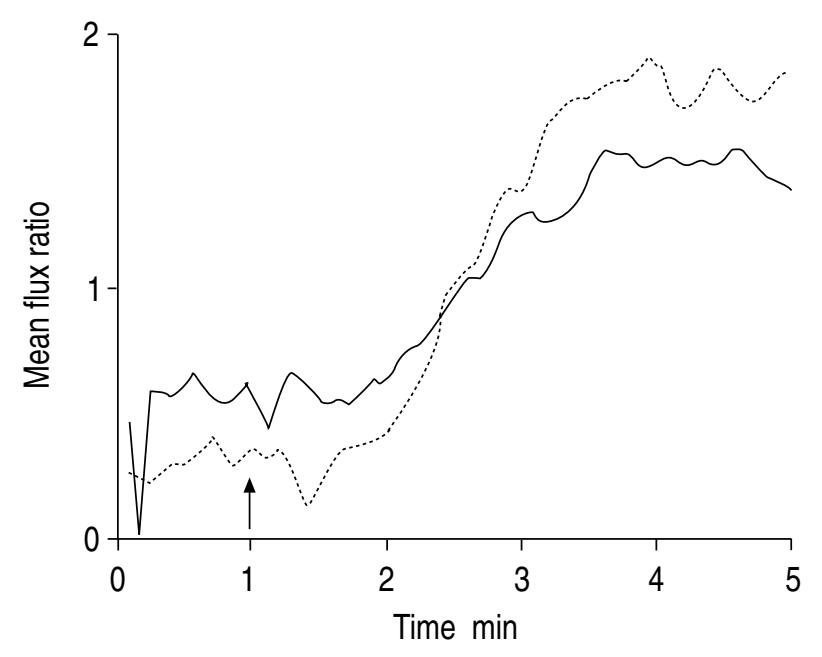

Fig. 5. - Comparison of the mean T-cell response, representing the Indo-1 blue/violet fluoresence ratio, depicting the mean calcium flux of splenic T-cells in the presence $(. . \cdots \cdots \cdot . .$.$) ) and absence (\longrightarrow)$ of PAMs upon activation. The calcium flux ratio was determined by evaluating levels of intracellular ionized calcium, as the change in blue: violet fluorescence after the addition of conA. The arrow indicates addition of the conA. For abbreviations see legend to figure 1 .

mean blue:violet ratio is calculated during the first minute following introduction of the sample into the cytometer flow cell (immediately prior to the addition of conA), and again during the 4-5 min period after introduction of conA at time $1 \mathrm{~min}$. The ratio of these two values defines the $\mathrm{Ca}^{++}$flux for a given sample.

The calcium flux of splenic derived T-cells in the absence of PAMs using CaI or conA was 5.0 \pm 0.6 and $1.8 \pm 0.4$, respectively $(n=4)$. The presence of PAMs in the T-cell culture for $2 \mathrm{~h}$ (and up to $10 \mathrm{~h}$, data not shown) prior to analysis did not alter the flux potential of the Tcells, where the resulting calcium flux after activation by $\mathrm{CaI}$ or conA was $4.5 \pm 0.5$ and $1.6 \pm 0.2$, respectively $(n=4)$. Comparable findings were also obtained using LN T-cells, and preliminary experiments employing mitogenic dosages of anti-CD3 produced results demonstrating comparable findings to those reported here for conA and CaI. The calcium flux ratio resulting after the addition of soluble anti-CD3 alone was 1.2 and 1.3, respectively, for $\mathrm{T}$-cells stimulated in the presence or absence of PAMs.

\section{Discussion}

Mounting evidence suggests that the maintenance of immunological homeostasis in the airways and peripheral lung relies primarily on endogenous immunosuppressive mechanisms, which collectively restrict the local induction of $\mathrm{T}$-cell responses, in the main, to antigenic challenges, posing a genuine threat to the host (reviewed in [2]). By extension, it has been postulated that the breakdown of these suppressive mechanisms may be important to the aetiology of immunologically-mediated diseases, such as respiratory allergy, and may also contribute to the pathogenesis of established disease $[2,26]$.
PAM-mediated suppression of T-cell activation is widely ascribed an important role in this process, and the in vitro evidence upon which this suggestion is based has been given recent support by the results of experiments on in situ depletion of PAMs in rats and mice, a manoeuvre which creates a state of immunological hyperreactivity to antigenic challenge via aerosol $[15,16]$.

The existence of similar relationships between PAM immunosuppressive function(s) and T-cell reactivity in human lung disease is yet to be conclusively demonstrated, but is increasingly supported by evidence from studies on PAM immunoregulatory activity in sarcoidosis [27-30], and to a lesser extent in bronchial asthma $[31,32]$, and chronic lower respiratory tract infection [33-35]. However, the existing evidence is sufficient to justify more detailed in vitro studies on the underlying mechanisms.

The present experiments focus on the early events during in vitro T-cell activation in the presence of PAMs at a density which completely inhibits T-cell proliferation. The salient findings are as follows; firstly, intracellular levels of free $\mathrm{Ca}^{++}$increase rapidly in T-cells following the addition of $\mathrm{CaI}$ or conA to the cultures, both in the presence and absence of PAMs. In addition, down-modulation of TcR-associated molecules (a normal consequence of T-cell activation) [36] occurs to a comparable degree in both cultures. Collectively, these results suggest that the activation process per se initially proceeds normally in the presence of PAMs. Consistent with this suggestion, both the $\alpha$ and $\beta$ receptors for IL-2 demonstrate comparable degrees of upregulation in the presence or absence of PAMs.

In this context, it has recently been reported that IL$2 \mathrm{R}$ expression (but not $\mathrm{T}$-cell proliferation) can occur independently of $\mathrm{Ca}^{++}$flux [37]. It also appears that the failure of the T-cells to proliferate in the presence of PAMs is not due to a lack of available IL-2, which was produced in levels approaching control cultures. Furthermore, the addition of excessive levels of rIL-2 to cultures containing PAMs does not induce T-cell proliferation.

This latter finding distinguishes the present phenomenon from classical T-cell anergy, a process in which unresponsiveness to in vitro restimulation is associated with failure to produce IL-2 [38]. However, it appears similar to a recent report of inhibition of in vitro T-cell responses in the presence of Type II alveolar epithelial cells, in which "suppressed" T-cells were unable to proliferate, despite expression of IL-2R and secretion of high levels of IL-2 [39]. In both the latter and the present model, T-cell activation up to the stage of cytokine release appears to proceed normally, but the activation process is arrested prior to cell division.

We have not yet established the degree to which these effects are reversible, nor the relationship between IL-2 and the full range of T-cell cytokines, but the reported experience with other manifestations of in vitro T-cell suppression [38] indicates that the effects upon other cytokines are likely to be highly variable. Experiments are in progress to determine the applicability of these findings to human alveolar macrophage (AM):T-cell interactions. A recent report [22] indicates variable effects 
of human AMs on T-cell IL-2R expression, but (analogous to the results above) failure of rIL-2 to inhibit AMmediated suppression. A single report [40] suggests AM-mediated inhibition of $\mathrm{Ca}^{++}$flux in human T-cells in response to anti-CD3 but not to ionomycin, in contrast to the consistent results reported above with both activating agents.

In summary, the present results and previous data on Type II alveolar epithelial cells point to the operation of a sophisticated control mechanism for T-cell activation in the lung, which may permit the local expression of a single "burst" of effector function in the form of cytokine release, whilst at the same time limiting the local amplification of the response via active suppression of subsequent proliferation of the activated cells.

\section{References}

1. Holt PG. Downregulation of immune responses in the lower respiratory tract: the role of alveolar macrophages. Clin Exp Immunol 1986; 63: 261-270.

2. Holt PG, McMenamin C. Defence against allergic sensitization in the healthy lung: the role of inhalation tolerance. Clin Exp Allergy 1989; 19: 255-262.

3. Rola-Plesczynski M. Immunoregulation by leukotrienes and other lipoxygenase metabolites. Immunol Today 1985; 6: 302-308.

4. Chandler DB, Fulmer JD. Prostaglandin synthesis and release by subpopulations of rat alveolar macrophages. J Immunol 1987; 139: 893-898.

5. Monick M, Glazier J, Hunninghake GW. Human alveolar macrophages suppress interleukin-1 (IL-1) activity via the secretion of prostaglandin $\mathrm{E}_{2}$. Am Rev Respir Dis 1987; 135: 72-77.

6. Roth MD, Golub SH. Human pulmonary macrophages utilize prostaglandins and transforming growth factor- $\beta_{1}$ to suppress lymphocyte activation. J Leukoc Biol 1993; 53: 366-371.

7. Moore SA, Strieter RM, Rolfe MW, Standiford TJ, Burdick MD, Kunkel SL. Expression and regulation of human alveolar macrophage-derived interleukin-1 receptor antagonist. Am J Respir Cell Mol Biol 1992; 6: 569-575.

8. Kawabe T, Isobe K-I, Hasegawa Y, Nakashima I, Shimokata K. Immunosuppressive activity induced by nitric oxide in culture supernatant of activated rat alveolar macrophages. Immunology 1992; 76: 72-78.

9. Daynes RA, Araneo BA, Dowell TA, Juang K, Dudley D. Regulation of murine lymphokine production in vivo. III. The lymphoid tissue microenvironment exerts regulatory influences over T-helper cell function. $J$ Exp Med 1990; 171: 979-996.

10. Sedgwick JD, Holt PG. Downregulation of immune responses to inhaled antigen: studies on the mechanism of induced suppression. Immunology 1985; 56: 635-642.

11. Holt PG, Schon-Hegrad MA, Oliver J. MHC class II antigen-bearing dendritic cells in pulmonary tissues of the rat. Regulation of antigen presentation activity by endogenous macrophage populations. J Exp Med 1988; 167: 262-274.

12. Holt PG, McMenamin C, Schon-Hegrad MA, et al. Immunoregulation of asthma: control of T-lymphocyte activation in the respiratory tract. Eur Respir J 1991; 4 (Suppl.): S6-15.
13. Strickland D, Thepen T, Kees U, Kraal G, Holt PG. Regulation of T-cell function in lung tissue by pulmonary alveolar macrophages. Immunology 1993; 80: 266-272.

14. Thepen T, Van Rooijen N, Kraal G. Alveolar macrophage elimination in vivo is associated with an increase in pulmonary immune response in mice. $J$ Exp Med 1989; 170: 499-509.

15. Thepen T, McMenamin C, Oliver J, Kraal G, Holt PG. Regulation of immune response to inhaled antigen by alveolar macrophages: differential effects of in vivo alveolar macrophage elimination on the induction of tolerance vs immunity. Eur J Immunol 1991; 21: 28452850.

16. Holt PG. Regulation of antigen-presenting function(s) in lung and airway tissues. Eur Respir J 1993; 6: 120129.

17. Mason DW, Arthur RP, Dallman MJ, Green JR, Spickett GP, Thomas ML. Functions of rat T-lymphocyte subsets isolated by means of monoclonal antibodies. Immunol Rev 1983; 74: 57-82.

18. Nicolls MR, Aversa GG, Pearce NW, et al. Induction of long-term specific tolerance to allografts in rats by therapy with an anti-CD3-like monoclonal antibody. Transplantation 1993; 55: 459-468.

19. Hünig T, Wallny HJ, Hartley JK, Lawetzky A, Tiefenthaler G. A monoclonal antibody to a constant determinant of the rat T-cell antigen receptor that induces T-cell activation. Differential reactivity with subsets of immature and mature T-lymphocytes. J Exp Med 1989; 169: 73-86.

20. Paterson DJ, Jefferies WA, Green JR, et al. Antigens of activated rat T-lymphocytes including a molecule of $50,000 \mathrm{Mr}$ detected only on CD4 positive T-blasts. $\mathrm{Mol}$ Immunol 1987; 24: 1281-1290.

21. Tellides G, Dallman MJ, Morris PJ. Mechanism of action of interleukin-2 receptor (IL-2R) monoclonal antibody $(\mathrm{MoAb})$ therapy: target cell depletion or inhibition of function? Transplant Proc 1989; 21: 429-430.

22. Schauble TL, Boom WH, Finegan CK, Rich EA. Characterization of suppressor function of human alveolar macrophages of T-lymphocyte responses to phytohemagglutinin: cellular selectivity, reversibility, and early events in T-cell activation. Am J Respir Cell Mol Biol 1993; 8: 89-97.

23. Rabinovitch PS, June CH, Grossmann A, Ledbetter JA. Heterogeneity among T-cells in intracellular free calcium responses after mitogen stimulation with PHA or anti-CD3. Simultaneous use of Indo-1 and immunofluoresence with flow cytometry. J Immunol 1986; 137: 952-961.

24. Deusch K, Daley JF, Levine H, et al. Differential regulation of $\mathrm{Ca}^{2+}$ mobilization in human thymocytes by coaggregation of surface molecules. J Immunol 1990; 144: 2851-2858.

25. Chilson OP, Kelly-Chilson AE. Mitogenic lectins bind to the antigen receptor on human lymphocytes. Eur $J$ Immunol 1989; 19: 389-396.

26. Holt PG, McMenamin C, Nelson D. Primary sensitisation to inhalant allergens during infancy. Ped Allergy Immunol 1990; 1: 3-13.

27. Lem VM, Lipscomb MF, Weissler JC, et al. Bronchoalveolar cells from sarcoid patients demonstrate enhanced antigen presentation. J Immunol 1985; 135: 1766-1771.

28. Venet A, Hance AJ, Saltini C, Robinson BWS, Crystal RG. Enhanced alveolar macrophage-mediated antigeninduced T-lymphocyte proliferation in sarcoidosis. J Clin Invest 1985; 75: 293-301. 
29. Poulter LW. Changes in lung macrophages during disease. FEMS Micro Immunol 1990; 64: 327-332.

30. Nagai S, Aung H, Takeuchi M, Kusume K, Izumi T. IL1 and IL-1 inhibitory activity in the culture supernatants of alveolar macrophages from patients with interstitial lung diseases. Chest 1991; 99: 674-680.

31. Gant V, Cluzel M, Shakoor Z, Rees PJ, Lee TK, Hamblin AS. Alveolar macrophage accessory cell function in bronchial asthma. Am Rev Respir Dis 1992; 146: 900-904.

32. Aubas P, Cosso B, Godard P, Michel FB, Clot J. Decreased suppressor cell activity of alveolar macrophages in bronchial asthma. Am Rev Respir Dis 1984; 130: 875878.

33. Fujiwara H, Kleinhenz ME, Wallis RS, Ellner JJ. Increased interleukin-1 production and monocyte suppessor cell activity associated with human tuberculosis. Am Rev Respir Dis 1986; 133: 73-77.

34. Twigg HL, Lipscomb MF, Yoffe B, Barbaro DJ, Weissler JC. Enhanced accessory cell function by alveolar macrophages from patients infected with the human immunodeficiency virus: potential role for depletion of $\mathrm{CD}^{+}$cell in the lung. Am J Respir Cell Mol Biol 1989; 1: $391-400$

35. Ina Y, Takada K, Yamamoto M, Morishita M, Yoshikawa
K. Antigen-presenting capacity of alveolar macrophages and monocytes in pulmonary tuberculosis. Eur Respir J 1991; 4: 88-93.

36. Cantrell DA, Verbi W, Davies A, Parker P, Crumpton MJ. Evidence that protein kinase $C$ differentially regulates the human T-lymphocyte CD2 and CD3 surface antigens. Eur J Immunol 1988; 18: 1391-1396.

37. Gelfand EW, Cheung RK, Grinstein S, Mills GB. Characterization of the role for calcium influx in mitogen-induced triggering of human T-cells. Identification of calciumdependent and calcium-independent signals. Eur J Immunol 1986; 16: 907-912.

38. O'Hehir RE, Yssel H, Verma S, de Vries JE, Spits H, Lamb JR. Clonal analysis of differential lymphokine production in peptide and superantigen-induced T-cell anergy. Int Immunol 1991; 3: 819-826.

39. Paine R, Mody CH, Chavis A, Spahr MA, Turka LA, Toews GB. Alveolar epithelial cells block lymphocyte proliferation in vitro without inhibiting activation. Am J Respir Cell Mol Biol 1991; 5: 221-229.

40. Yarbrough WC, Wilkes DS, Weissler JC. Human alveolar macrophages inhibit receptor-mediated increases in intracellular calcium concentration in lymphocytes. $A m$ J Respir Cell Mol Biol 1991; 5: 411-415. 